\title{
Height Estimation Based on Foot Length and Breadth in Children, Teenager, and Adult in Bandung City, Indonesia
}

\author{
Sani Tanzilah*, Noorman Herryadi*, Andri A. Rusman** \\ *Forensic and Legal Medicine Department \\ Faculty of Medicine Padjadjaran University \\ Jl.Eijkman no 38 Bandung 40161 Indonesia \\ **Forensic and Legal Medicine Laboratory \\ Faculty of Medicine Ahmad Yani University \\ Terusan Jend. Sudirman PO. BOX 148 Cimahi 40533 Indonesia \\ Email: sani.tz72@gmail.com
}

\begin{abstract}
Stature estimation is important for forensic identification, particularly in dismembered body. The equation used to estimate the height of a population is not necessarily applicable to other populations (population spesific). This study was conducted to generate the linear regression equation for stature estimation based on foot length and foot breadth on the population in the city of Bandung. This cross-sectional study is conducted to 908 people, consisting of three age groups (children, adolescents, adults), in the city of Bandung. Sampling was done by multistage sampling. The stature was measured using a stadiometer SECA 213, right foot length (RFL), right foot breadth ( $R F B)$, left foot length (LFL), and left foot breadth (LFB) were measured using sliding calipers. Data were analyzed with SPSS version 21.0 for Windows. There is correlation between height with the $R F L, R F B, L F L$, and LFB. In contrast to the group of teenagers and adults, there is no boys-girls difference between height, RFL, RFB, LFL, and LFB. 21 regression equation for stature estimation based on the foot size. Stature estimation can be done using the linear regression equation based on the foot length and foot breadth, according to population, gender, and age of the subject being examined.
\end{abstract}

Key words: height estimation, foot length, foot breadth 


\title{
Estimasi Tinggi Badan Berdasarkan Panjang dan Lebar Telapak Kaki pada Kelompok Usia Anak, Remaja, dan Dewasa di Kota Bandung, Indonesia
}

\author{
Sani Tanzilah*, Noorman Herryadi*, Andri A. Rusman** \\ *Departemen Forensik dan Kedokteran Legal \\ Fakultas Kedokteran Universitas Padjadjaran \\ J1.Eijkman no 38 Bandung Indonesia \\ **Laboratorium Forensik dan Kedokteran Legal \\ Fakultas Kedokteran Universitas Ahmad Yani \\ Terusan Jend. Sudirman PO BOX 148 Cimahi 40533 \\ Email: sani.tz72@gmail.com
}

\begin{abstract}
Abstrak
Estimasi tinggi badan merupakan salah satu hal penting dalam identifikasi jenazah, terutama yang tidak utuh. Persamaan yang digunakan untuk estimasi tinggi badan suatu populasi belum tentu dapat diterapkan di populasi lain (population spesific). Penelitian ini dilakukan untuk menghasilkan persamaan regresi linier estimasi tinggi badan berdasarkan panjang dan lebar kaki pada populasi di kota Bandung. Penelitian dilakukan secara cross-sectional terhadap 908 orang, yang terdiri atas 3 kelompok usia (anak, remaja, dewasa), di kota Bandung. Pengambilan sampel dilakukan dengan cara multistage sampling. Dilakukan pengukuran tinggi badan menggunakan stadiometer SECA 213, pengukuran panjang kaki kanan (Right foot Length/RFL), lebar kaki kanan (Right foot breadth/RFB), panjang kaki kiri (Left Foot Length/LFL), dan lebar kaki kiri (Left foot breadth/LFB) menggunakan kaliper geser. Data dianalisis dengan SPSS Versi 21.0 for windows. Terdapat korelasi antara tinggi badan dengan $R F L, R F B, L F L$, dan $L F B$. Berbeda dengan kelompok remaja dan dewasa, tidak terdapat perbedaan antara tinggi badan, $R F L, R F B, L F L$, dan $L F B$ antara anak laki-laki dan perempuan. Didapatkan 21 persamaan regresi linier sederhana dan berganda untuk estimasi tinggi badan berdasarkan variabel ukuran kaki. Estimasi tinggi badan dapat dilakukan menggunakan persamaan regresi linier berdasarkan panjang dan lebar kaki, sesuai dengan populasi, jenis kelamin, dan usia subjek yang diperiksa.
\end{abstract}

Kata kunci: estimasi tinggi badan, panjang kaki, lebar kaki 


\section{Research Article}

\section{Pendahuluan}

Identifikasi merupakan salah satu proses penting dalam pemeriksaan post-mortem di bidang kedokteran forensik. $^{1-4}$ Identifikasi melalui pemeriksaan profil biologis dilakukan dengan pengelompokan dan perbandingan dengan data semasa hidup (ante-mortem). Estimasi tinggi badan merupakan salah satu profil biologis dasar yang penting dalam identifikasi, selain jenis kelamin, tinggi badan, ras/ancestry, dan usia. ${ }^{5-6}$ Penentuan tinggi badan pada jenazah utuh dapat dilakukan dengan metode anatomi. ${ }^{7}$ Pada jenazah tidak utuh, diperlukan metode yang berbeda untuk mengidentifikasi bagian-bagian tubuh manusia (human remains). ${ }^{13,6,8}$ Pada kondisi seperti ini, para ahli biasanya menggunakan metode matematika. ${ }^{7}$ Dalam estimasi tinggi badan dari ukuran tangan dan kaki, analisis regresi lebih baik dibandingkan multiplication factor. ${ }^{7}$

Metode penentuan tinggi badan pada umumnya bersifat spesifik di suatu area geografis (population spesific), pada waktu tertentu. ${ }^{9}$ Selain itu, terdapat perbedaan ukuran dan morfologi pada tubuh laki-laki dan perempuan karena adanya dimorfisme seksual. ${ }^{10,11}$ Meskipun telah terdapat penelitian sebelumnya mengenai estimasi tinggi badan berdasarkan panjang dan atau lebar kaki, namun persamaan yang telah dihasilkan belum tentu dapat diterapkan pada populasi lain. Penelitian ini bertujuan untuk menghasilkan rumus atau persamaan linear yang dapat digunakan untuk estimasi tinggi badan pada populasi di kota Bandung pada tiga kelompok usia dan masing-masing jenis kelamin.

Penelitian mengenai estimasi tinggi badan dari panjang dan lebar kaki antara lain telah dilakukan oleh Kewal Krishan (2007) di Gujjar ${ }^{3}$, Hilmi Ozden dkk. (2004) di Universitas Osmangazi, Turki ${ }^{12}$, Mansur DI dkk. (2012) di Kathmandu, Nepal ${ }^{4}$, TB Grivas (2007) di Attica, Yunani, tahun 1996-2005. ${ }^{13}$ Di Indonesia, penelitian-penelitian mengenai korelasi tinggi badan dengan ukuran kaki pernah dilakukan oleh Iwan Aflanie (2007) di Yogyakarta ${ }^{14}$, serta estimasi tinggi badan berdasarkan ukuran kaki oleh Warih Wilianto dan Agus M. Alghozi (2010) di Surabaya. ${ }^{15}$ Penelitian ini umumnya dilakukan terhadap satu kelompok usia. Persamaan regresi estimasi tinggi badan untuk populasi Jawa Barat belum ada. Signifikansi perbedaan hasil estimasi rumus suatu populasi jika digunakan pada populasi lain dalam lingkup geografis yang relatif berdekatan belum diketahui. 


\section{Research Article}

Tabel 1 Beberapa Penelitian Estimasi Tinggi Badan Berdasarkan Ukuran Kaki

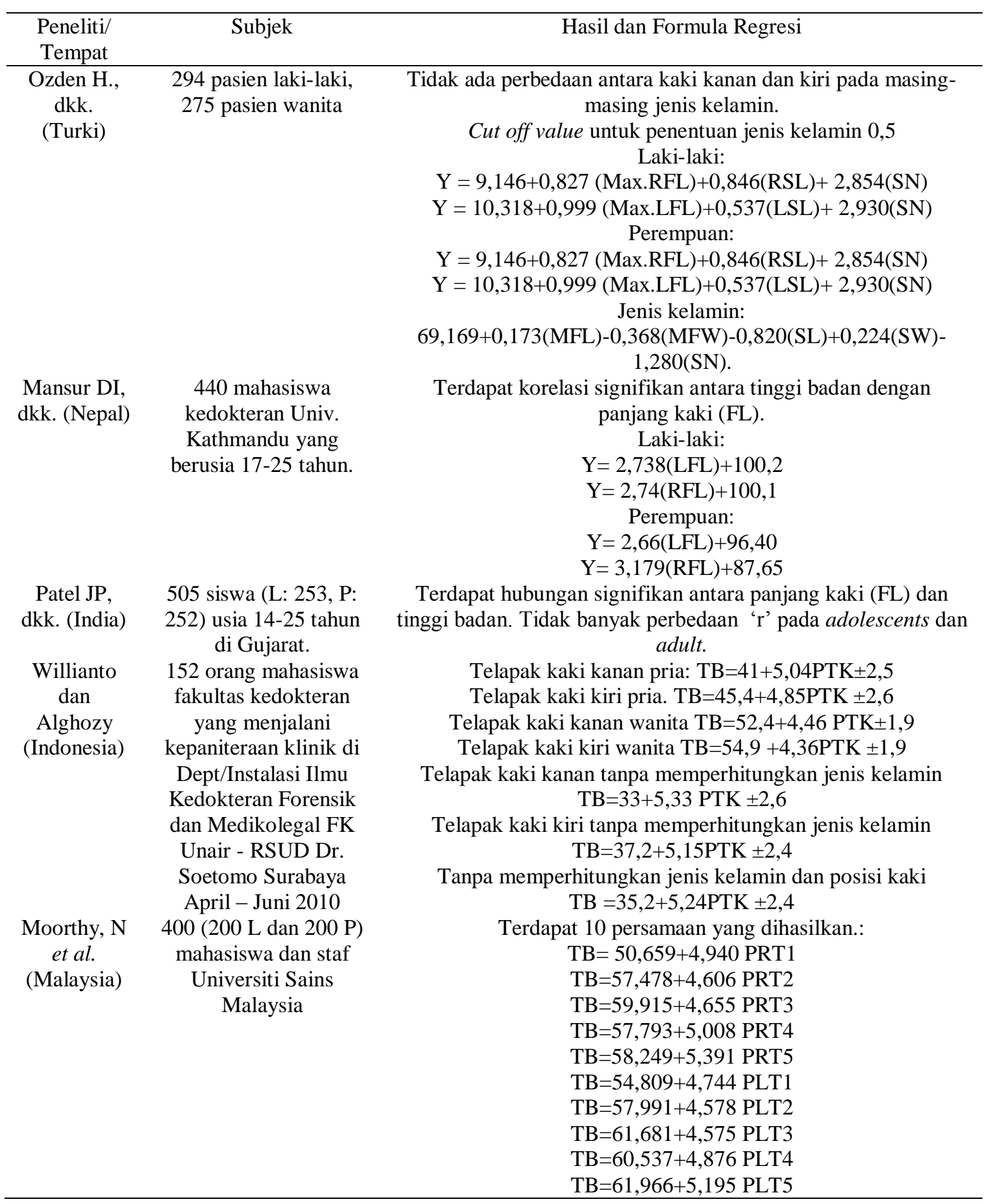

\section{Metode}

Penelitian ini merupakan penelitian analitik kuantitatif menggunakan metode crosssectional.Jumlah sampel sebanyak 908 orang, terdiri dari 510 orang perempuan dan 398 orang lakilaki, berusia 7-25 tahun, dan terbagi menjadi 3 kelompok usia, yaitu: 


\section{Research Article}

1. Kelompok anak (children), rentang usia 7-12 tahun

2. Kelompok remaja (adolescent), rentang usia 13-17 tahun

3. Kelompok dewasa (adult), lebih dari 18 tahun.

Penelitian berlangsung di kota Bandung, pada bulan Agustus hingga Desember 2014. Pengambilan sampel dilakukan dengan cara multistage random sampling, dengan unit sampel Sekolah Dasar (SD), Sekolah Menengah Pertama (SMP), Sekolah Menengah Atas (SMA), dan Universitas di kota Bandung yang terpilih secara random. Persetujuan etik diperoleh dari komisi etik penelitian kesehatan FK Unpad No. 69/UN6.C2.1.2/KEPK/PN/2014.

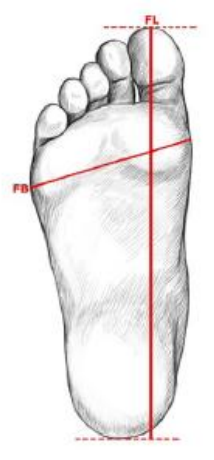

\section{Gambar 1. Panjang dan Lebar Kaki}

Data didapatkan dari pengukuran tinggi badan, panjang, dan lebar kaki kanan, panjang dan lebar kaki kiri. Pengukuran dilakukan dalam satuan sentimeter dengan tingkat ketelitian $0,1 \mathrm{~cm}$. Pengukuran tinggi badan dilakukan menggunakan stadiometer portabel SECA 213, sedangkan pengukuran panjang dan lebar kaki (Gambar 1) dilakukan menggunakan kaliper geser. Panjang kaki merupakan jarak antara bagian paling luar tumit (pternion) ke ujung ibu jari kaki atau ujung jari kedua (acropodian). ${ }^{17-18}$

Pengukuran tinggi badan dilakukan pada posisi berdiri tegak tanpa alas kaki, kedua tumit saling menempel. Bahu, punggung, bokong menempel ke dinding, posisi kepala tegak (Frankfort horizontal plane). Selanjutnya, headboard digerakkan sampai menyentuh puncak kepala. ${ }^{19}$ Pengukuran panjang kaki dilakukan dengan mengukur jarak maksimum antara bagian paling anterior dan posterior kaki (Gambar 2). Pengukuran lebar kaki dilakukan dengan mengukur jarak antara prominensia medialis di metatarsophalangeal (MTP) I dan prominensia lateralis di MTP V. ${ }^{19}$ (Gambar 2) 


\section{Research Article}

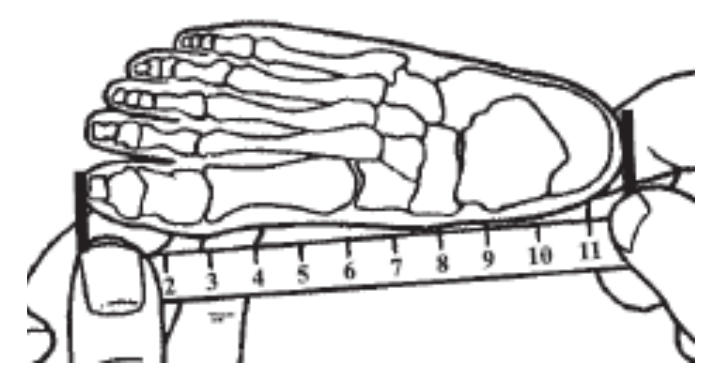

Gambar 2. Metode Pengukuran Panjang (kiri) dan Lebar Kaki (kanan) ${ }^{19}$

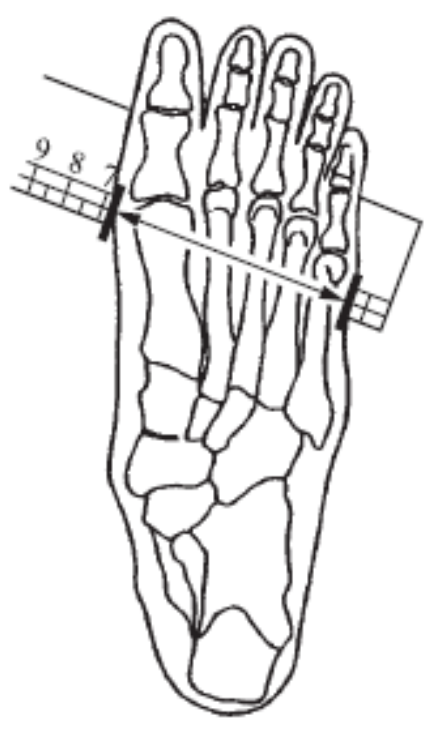

Hasil pengukuran ditulis pada kertas yang telah dibubuhkan data subjek yang diperiksa. Data tersebut lalu direkapitulasi secara terkomputasi. Dara hasil pengukuran dianalisis secara statistik menggunakan SPSS versi 21.0 for windows. Analisis data terdiri dari analisis data univariat untuk mendeskripsikan variabel dan mengetahui karakteristik dan subjek yang menjadi sampel penelitian. Selanjutnya, dilakuka analisis bivariat berupa uji korelasi untuk mengetahui hubungan antarvariabel. Setelah analisis bivariat, maka dilanjutkan dengan analisis multivariat menggunakan regresi linear multipel. Pada analisis data penelitian ini digunakan uji non-parametrik mann-whitney untuk mengetahui perbedaan variabel-variabel dan jenis kelamin pada masing-masing kelompok usia.

\section{Hasil}

Didapatkan data panjang kaki kanan (Right Foot Length/RFL), lebar kaki kanan (Right Foot Breadth/RFB), panjang kaki kiri (Left Foot Length/LFL), dan lebar kaki kiri (Left Foot Breadth/LFB). 
Vol. 1 No. 4. August 2016

Research Article

Tabel 2 Perbandingan Tinggi Badan, $R F L, R F B, L F L$ dan $L F B$ dengan Jenis Kelamin pada Usia Anak, Remaja, dan Dewasa

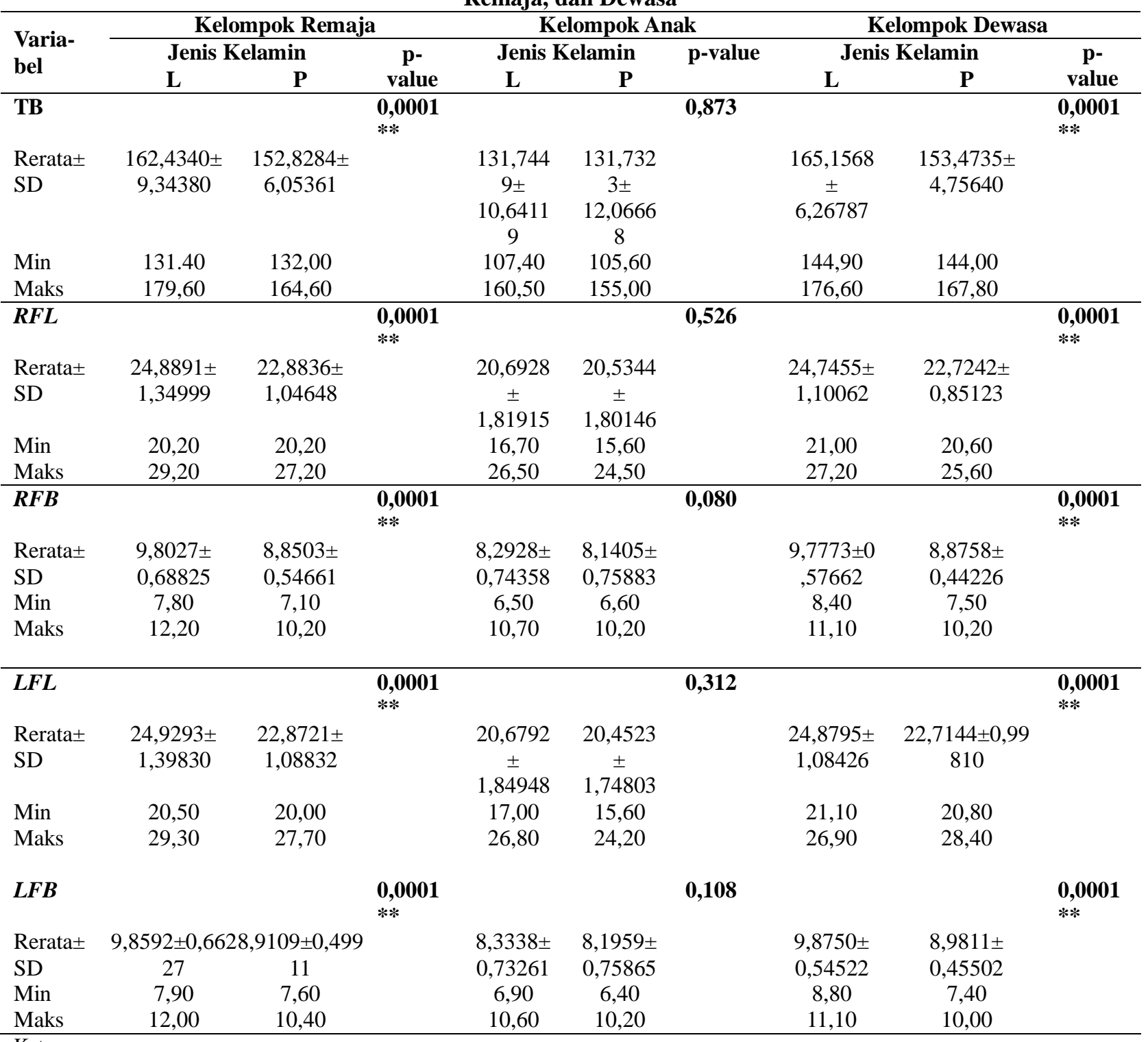

Keterangan:

Digunakan uji statistik non-parametrik mann-Whitney. Nilai kemaknaan berdasarka nilai $\mathrm{p}<0,05$

Tanda* menunjukkan nilai $\mathrm{p}<0,05$ artinya signifikan atau bermakna secara statistik.

RFL: Right foot Length, RFB: Right foot breadth, LFL: Left Foot Length, LFB: Left foot breadth

Min: minimum

Maks: maksimum 


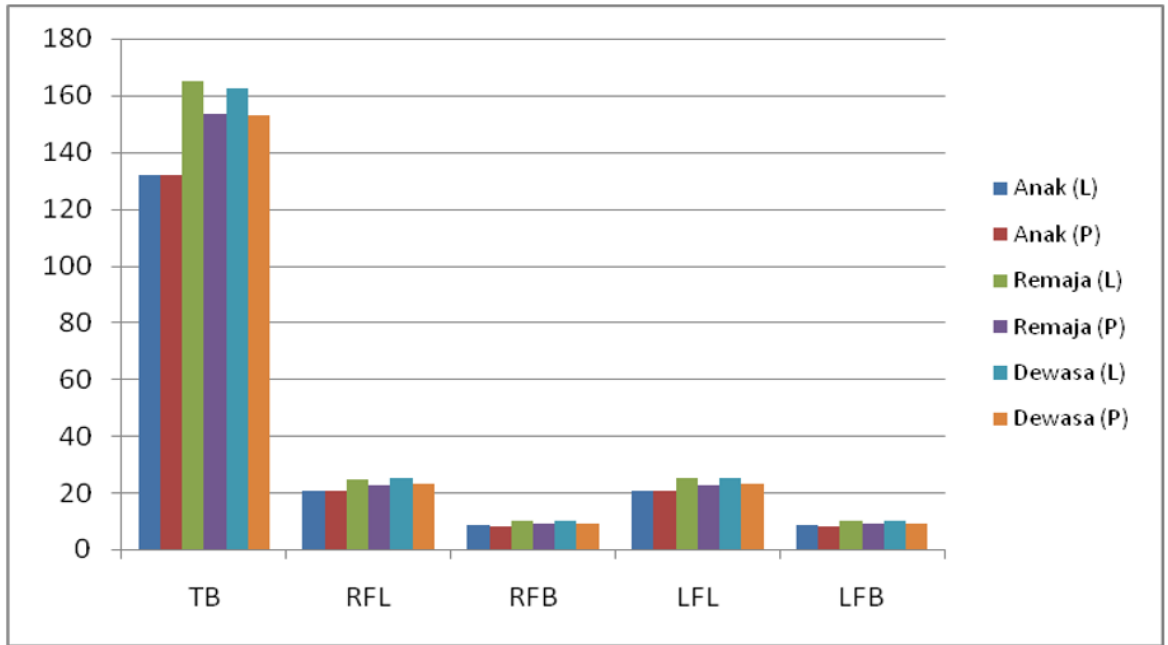

Gambar 3 Rerata Tinggi Badan dan Ukuran Kaki Anak, Remaja, dan Dewasa

Tabel 3 Nilai Korelasi antara Tinggi Badan dengan Panjang Kaki dan Lebar Kaki pada Kelompok Anak, Remaja, dan Dewasa

\begin{tabular}{|c|c|c|c|}
\hline \multirow{2}{*}{ Korelasi TB dengan } & \multicolumn{3}{|c|}{ Nilai R } \\
\hline & Anak & Remaja & Dewasa \\
\hline$R F L$ & $0,946^{*}$ & $0,794 *$ & $0,790 *$ \\
\hline$R F B$ & $0,798 *$ & $0,626^{*}$ & $0,524 *$ \\
\hline$L F L$ & $0,944 *$ & $0,819 *$ & $0,780^{*}$ \\
\hline$L F B$ & $0,810^{*}$ & $0,668^{*}$ & $0,578 *$ \\
\hline
\end{tabular}




\section{Research Article}

Tabel 4 Persamaan Regresi Linier Tinggi Badan Berdasarkan RFL, RFB, LFL, dan LFB

\begin{tabular}{|c|c|c|c|}
\hline \multirow[b]{2}{*}{ Variabel } & \multicolumn{3}{|c|}{ Persamaan Regresi Linier } \\
\hline & Laki-laki & Perempuan & Unknown \\
\hline RFL, & $\mathrm{TB}=-4,336+2,539 \mathrm{RFL}-$ & $\mathrm{TB}=-11,196+3,439 \mathrm{RFL}-$ & $\mathrm{TB}=-2,591+$ \\
\hline RFB, & $0,254 \mathrm{RFB}+4,180 \mathrm{LFL}+0,093 \mathrm{~L}$ & 0,457RFB+ 3,314LFL+ & 3,467RFL-0,995RFB \\
\hline $\begin{array}{l}\text { LFL, } \\
\text { LFB }\end{array}$ & $\mathrm{FB}+\sum$ & $1,384 \mathrm{LFB}+\sum$ & $\begin{array}{c}+3,355 \mathrm{LFL}+0,586 \mathrm{LFB} \\
+\sum\end{array}$ \\
\hline $\begin{array}{l}\text { RFL, } \\
\text { RFB }\end{array}$ & 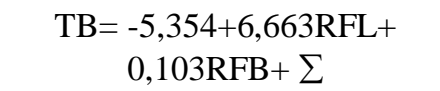 & $\begin{array}{c}\mathrm{TB}=-10,216+6,820 \mathrm{RFL}+ \\
0,640 \mathrm{RFB}+\sum\end{array}$ & $\begin{array}{c}\mathrm{TB}=-2,990+6,815 \mathrm{RFL}- \\
0,348 \mathrm{RFB}+\sum\end{array}$ \\
\hline LFL, & $\mathrm{TB}=-3,030+6.577 \mathrm{LFL}$ & $\mathrm{TB}=-8,826+6,405 \mathrm{LFL}+$ & $\mathrm{TB}=-0,545+6,519 \mathrm{LFL}-$ \\
\hline LFB & $+0,045 \mathrm{LFB}+\sum$ & $1.554 \mathrm{LFB}+\sum$ & $0,133 \mathrm{LFB}+\sum$ \\
\hline RFL & $\mathrm{TB}=-5,259+6,700 \mathrm{RFL}+\sum$ & $\mathrm{TB}=-9,155+7,022 \mathrm{RFL}+\sum$ & $\begin{array}{c}\mathrm{TB}=- \\
3,345+6,694 \mathrm{RFL}+\sum\end{array}$ \\
\hline RFB & $\mathrm{TB}=7,778+15,419 \mathrm{RFB}+\sum$ & $\mathrm{TB}=26,528+13,791 \mathrm{RFB}+\sum$ & $\begin{array}{c}\mathrm{TB}= \\
21,117+14,204 \mathrm{RFB}+\sum\end{array}$ \\
\hline LFL & $\mathrm{TB}=-2,982+6,593 \mathrm{LFL}+\sum$ & $\mathrm{TB}=-6,277+6,902 \mathrm{LFL}+\sum$ & $\begin{array}{c}\mathrm{TB}=- \\
0,394+6,565 \mathrm{LFL}+\sum\end{array}$ \\
\hline LFB & $\mathrm{TB}=5,008+15,634 \mathrm{LFB}+\sum$ & $\mathrm{TB}=17,853+14,681 \mathrm{LFB}+\sum$ & $\begin{array}{c}\mathrm{TB}= \\
15,850+14,669 \mathrm{LFB}+\sum\end{array}$ \\
\hline
\end{tabular}

\section{Diskusi}

Dari hasil penelitian, terlihat bahwa terdapat perbedaan antara tinggi badan, panjang kaki kanan, lebar kaki kanan, panjang kaki kiri, lebar kaki kiri dengan jenis kelamin. Perbedaan ini terdapat pada kelompok gabungan, usia remaja, dan usia dewasa.

Tidak terdapat perbedaan yang signifikan antara tinggi badan anak laki-laki dan anak perempuan $(\mathrm{p}=0.873)$, panjang kaki kanan $(\mathrm{p}=0,526)$, lebar kaki kanan $(\mathrm{p}=0,080)$, panjang kaki kiri $(\mathrm{p}=0,312)$, lebar kaki kiri $(\mathrm{p}=0,108)$ dengan jenis kelamin pada kelompok usia anak. Rerata tinggi badan serta panjang dan lebar kaki anak laki-laki dan perempuan nyaris sama. Dari hasil penelitian ini diketahui pula terdapat korelasi antara tinggi badan danpanjang kaki kanan, lebar kaki kanan, panjang kaki kiri, dan lebar kaki kiri, dengan kekuatan korelasi yang bervariasi dari korelasi moderat hingga korelasi sangat kuat.

Pada kelompok anak, terdapat korelasi yang sangat kuat antara tinggi badan dengan panjang kaki kanan dan panjang kaki kiri. Dari tabel 3 terlihat bahwa koefisien korelasi antara tinggi badan dengan panjang kaki kanan dan panjang kaki kiri lebih besar (>0.9). Pada kelompok remaja dan dewasa, tinggi badan memiliki korelasi yang lebih kuat dengan panjang kaki kanan dan kiri dibandingkan dengan lebar kaki kanan dan kiri. Begitu pula pada kelompok usia dewasa, tinggi badan memiliki korelasi yang lebih 


\section{Research Article}

kuat dengan panjang kaki kanan dan kiri. Hal ini sesuai dengan penelitian yang dilakukan Zeybek dkk (Turki: 2008) ${ }^{8}$, Ozaslan dkk (Turki:2012) ${ }^{16}$, dan Khairulmazidah dkk (Malaysia: 2013) ${ }^{20}$, yang menunjukkan bahwa ukuran panjang kaki memiliki korelasi yang lebih besar dengan tinggi badan daripada ukuran lebar kaki. ${ }^{13,16,20}$

Pada tabel 2, terlihat bahwa terdapat perbedaan yang signifikan $(\mathrm{p}=0,0001)$ antara tinggi badan, $R F L, R F B$, $L F L$, dan $L F B$ antar kelompok usia. Penelitian lintas usia mengenai estimasi tinggi badan berdasarkan ukuran kaki pernah dilakukan pula oleh Patel, dkk (Gujarat: 2012). Penelitian tersebut menyatakan bahwa koefisien korelasi antara tinggi badan dengan panjang kaki pada kelompok usia remaja dan dewasa tidak jauh berbeda. ${ }^{21}$

Persamaan regresi linier untuk estimasi tinggi badan yang dihasilkan dari penelitian ini adalah rumus regresi multipel. Berdasarkan penelitian yang dilakukan Ozaslan dkk, penggunaan regresi linear multipel (menggunakan lebih dari satu variabel) memiliki Standard Error Estimation yang lebih kecil dibandingkan penggunaan regresi linear sederhana. ${ }^{16} \mathrm{Hal}$ ini berarti estimasi tinggi badan dengan regresi linier multipel akan lebih mendekati tinggi badan aktual dibandingkan estimasi tinggi badan menggunakan regresi linier sederhana.

\section{Simpulan}

Estimasi tinggi badan berdasarkan panjang dan lebar kaki dapat dilakukan dengan menggunakan regresi linier, baik multipel maupun berganda. Estimasi tinggi badan sebaiknya didahului dengan penentuan jenis kelamin, sehingga dapat diterapkan persamaan yang tepat, terutama pada kelompok usia remaja dan dewasa.

\section{Daftar Pustaka}

1. Kanchan T, Krishan K, Sharma A, Menezes RG. A study of correlation of hand and foot dimensions for personal identification in mass disasters. Forensic Science International.2010;112:e1-e6.

2. Moudgil R, Kaur R, Menezes RG, Kanchan T, Garg RK. Foot index: Is it a tool for sex determination? Journal of Forensic and Legal Medicine.2008;15:223-6.

3. Krishan K, Kanchan T, Passi N. Estimation of stature from the foot and its segments in a sub-adult female population of North India. J Foot Ankle Res.2011;4(24)

4. Mansur D, Haque M, Sharma K, Karki R, Khanal K, Karna R. Estimation of Stature from Foot Length in Adult Nepalese Population and its Clinical Relevance. Kathmandu Univ Med J.2012;37(1):16-9.

5. Saukko P, Knight B. The establishment of identity of human remains. In: Saukko P, editor. KNIGHT'S Forensic Pathology. Edisi ke- 3.Hodder Arnold. London;2004. p.98.

6. Jurmain R, Kilgore L, Trevanthan W. Essentials of Physical Anthropology 8ed. MItchell E, editor. Wardsworth CENGAGE Learning. Belmont;2011.

7. Krishan K, Kanchan T, Sharma A. Multiplication factor versus regression analysisi in strarure estimation from hand and foot dimension. Journal of Forensic and Legal Medicine.2012;(19):211-4. 


\section{Research Article}

8. Zeybek G, Ergur I, Demiroglu Z. Stature and gender estimation using foot measurements. Forensic Science International.2008;181(54):e1-.e5.

9. Simmons T, Haglund WD. Anthropology in a forensic context. Dalam: Hunter J, Cox M, editors. Forensic Archaeology: Advances in Theory and Practice. Routledge. London;2005.p.159-76.

10. Pickering R, Bachman D. The Use of Forensic Anthropology. 2 ed. Boca Raton: CRC Press;2009.

11. Houck M, Siegel J. Fundamentals of FORENSIC SCIENCE 2ed. Oxford: Elsevier;2010.

12. Ozden H, Balci Y, Demirustu C, Turgut A, Ertugrul M. Stature and sex estimate using foot and shoe dimension. Forensic Science International.2004;(147):181-4.

13. Grivas TB, Mihas C, Arapaki A, Vasiliadis E. Correlation of foot length with height and weight in school age children. J Forensic Leg Med.2008;15(2).

14. Aflanie I. Perbandingan korelasi penentuan tinggi badan antara metode pengukuran panjang tibia perkuataneus dan panjang telapak kaki. Yogyakarta: Universits Gajah Mada;2007.

15. Alghozi A, Wilianto W. Perkiraan tinggi badan berdasar panjang telapak kaki pada populasi mongoloid dewasa di indonesia. Majalah kedokteran forensik Indonesia.2010.p.42-5.

16. Ozaslan A, Karadayi B, Kolusayin MO, Kaya A, Afsin H. Predictive role of hand and foot dimensions in stature estimation. Rom J Leg Med.2012;20:41-6.

17. Marko RS, Dubey A, Shrivastava S. To Compare Reliability and Accuracy of Foot Length and Hand Length in Estimation of Stature in North Indian Adults. J Evol Med Dent Sci.2014;3(26):7290-5.

18. Krishan K. Estimation of stature from footprint and foot outline dimensions in Gujjars of North India. Forensic Science International.2008;175:93-101. 